\title{
Multimodal Lexicography: The Representation of Meaning in Electronic Dictionaries
}

\author{
Robert Lew, Department of Lexicology and Lexicography, School of English, \\ Adam Mickiewicz University, Poznań, Poland (rlew@amu.edu.pl)
}

\begin{abstract}
One finding of user studies is that information on meaning tends to be what dictionary users want most from their dictionaries. This is consistent with the traditional image of the dictionary as a repository of meanings of words, and this is also borne out in definitions of the item DICTIONARY itself as given in dictionaries. While this popular view has not changed much, the growing role of electronic dictionaries can change the lexicographers' approach to meaning representation. Traditionally, paper dictionaries have explained words with words, using either a definition or an equivalent, and occasionally a line-drawn picture. However, a prominent feature of the electronic medium is its multimodality, and this offers potential for the description of meaning. While it is much easier to include pictorial content, electronic dictionaries can also hold media objects which paper cannot carry, such as audio, animation or video. Publishers are drawn by the attraction of these new options, but are they always functionally useful for the dictionary users? In this article, the existing evidence is examined, and informed guesses are offered where evidence is not yet available.
\end{abstract}

Keywords: ELECTRONIC DICTIONARY, MEANING, ILLUSTRATION, ANIMATION, AUDIO, SOUND EFFECTS, VIDEO, MULTIMODALITY, SPECIALIZED LEXICOGRAPHY, LEARNER'S DICTIONARY

Opsomming: Multimodale leksikografie: Die voorstelling van betekenis in elektroniese woordeboeke. Een bevinding van gebruikerstudies is dat inligting oor betekenis dit blyk te wees wat woordeboekgebruikers die meeste van hul woordeboeke verlang. Dit is in ooreenstemming met die tradisionele beeld van die woordeboek as 'n bewaarplek van die betekenisse van woorde, en dit word ook bevestig deur die definisies van die item WOORDEBOEK self soos aangebied in woordeboeke. Terwyl hierdie populêre siening nie veel verander het nie, kan die toenemende rol van elektroniese woordeboeke leksikograwe se benadering tot betekenisvoorstelling verander. Tradisioneel het papierwoordeboeke woorde met woorde verduidelik deur ó ' $n$

* This article includes some ideas and content from two plenary lectures of the author presented at the First International Symposium on Lexicography and L2 Teaching which took place at the Guangdong University of Foreign Studies, Guangzhou, China, 26-28 November 2008, and at the Fifteenth International Conference of the African Association for Lexicography which took place at the University of Botswana, Gaborone, Botswana, 19-21 July 2010. 


\begin{abstract}
definisie, óf 'n ekwivalent te gebruik, en soms 'n lyngetekende illustrasie. 'n Opvallende kenmerk van die elektroniese medium is sy multimodaliteit, en dit bied 'n moontlikheid vir die beskrywing van betekenis. Terwyl dit baie makliker is om illustratiewe inhoud in te sluit, kan elektroniese woordeboeke ook mediaobjekte bevat wat papier nie kan oordra nie, soos oudio, animasie en video. Uitgewers word aangetrek deur hierdie nuwe keuses, maar is hulle altyd funksioneel nuttig vir die woordeboekgebruikers? In hierdie artikel word bestaande getuienis ondersoek en ingeligte raaiskote aangebied waar getuienis nog nie beskikbaar is nie.
\end{abstract}

Sleutelwoorde: ELEKTRONIESE WOORDEBOEK, BETEKENIS, ILLUSTRASIE, ANIMASIE, OUDIO, KLANKEFFEKTE, VIDEO, MULTIMODALITEIT, GESPESIALISEERDE LEKSIKOGRAFIE, AANLEERDERSWOORDEBOEK

\title{
1. Introduction
}

\subsection{Lexicography: words and beyond}

Traditionally (as well as etymologically), lexicography is about words. Words (in the various technical senses of this general-language term) are the primary objects of description of dictionaries. But words are not just the thing being described; they have also remained the most important instrument of the dictionary-maker in the very job of describing. Words, then, have figured prominently on both sides of the lexicographic equation.

The questions addressed in this article are the following: How does the current transition of dictionaries to the electronic medium affect the role of the traditional verbal orientation of lexicography? Will the shift to the electronic mode lead to words being used in a different way in lexicographic explanation? Finally, how can dictionaries transcend words and employ other modalities: static and animated graphics, audio recordings, video sequences? ${ }^{1}$

\subsection{Meaning as a central notion in lexicography}

Dictionary users have varying needs when consulting dictionaries, and those needs are naturally dependent on personal preferences, but also, or perhaps primarily, on the specific task in which dictionary users happen to be involved, and circumstances of consultation. This much is clear from the accumulated body of user research, but what we also learn from such research is that there is one consultation need that clearly dominates, whatever the users' mother tongue, nationality, or proficiency level. What users want most from their dictionaries much of the time is meaning. This finding finds support in dictionary definitions themselves, such as the one given under the entry dictionary in the (online version of the) Cambridge Dictionary for Advanced Learners (CALD2, Walter 2005): 


\section{dictionary}

noun [C]

1 a book that contains a list of words in alphabetical order with their meanings explained or written in another language, or a similar product for use on a computer

If we agree that meaning is a key element in a lexicographic work, if follows that lexicographers should give their most careful attention to the treatment of meaning, so that they can satisfy the primary need of dictionary users. Traditional printed dictionaries have used a repertoire of devices for representing meaning in paper dictionaries, most of them having to do with words. As electronic dictionaries grow in importance, this repertoire can be extended, but also some of the traditional modes of meaning provision may be used in somewhat different ways. I will begin with the latter issue, gradually expanding the range of explanatory modes as we move on.

\section{Modes of meaning indication in dictionaries}

\subsection{Verbal mode}

The dominant way of indicating meaning in dictionaries has been verbal explanation, which relies on words. Such explanation, however, can take a number of forms which can be used alone or in combination.

\subsubsection{Definition}

Definition is clearly the most common and prototypical carrier of meaning in monolingual dictionaries; normally, a definition is a paraphrase of a lexical unit being defined by means of a more elaborate syntactic construction, but a number of interesting variations are possible (Wierzbicka 1985; Hanks 1987; Lew and Dziemianko 2006; Fabiszewski-Jaworski and Grochocka 2010). Definition has managed to stand the test of time: as such, it has endured for many centuries of lexicographic practice across a variety of dictionary cultures, and so there is no good reason why it should not be allowed to play a prominent role in modern electronic dictionaries. Still, it is interesting to reflect on its role in the new technological context afforded by electronic dictionaries.

\subsubsection{Defining vocabulary}

In the very popular English learners' dictionaries, definitions are now usually written using a restricted defining vocabulary of some twenty five hundred (give or take a few hundred) items (for a detailed historical account of the socalled vocabulary control movement, see Cowie 1999). The chief motivation behind the idea is that restricted-vocabulary definitions should be easier to understand for foreign learners, although there may be unexpected benefits to 
native speakers as well (McCreary and Amacker 2006). However, there are down sides, too, and here is one of them: by limiting the choice of words you can use in the definition to the basic set of most common words in their most common meanings, you tend to lose some of the discriminating power to tease out the finer shades of meaning. In actual lexicographic practice, there are cases when it is extremely difficult to avoid using a word from outside the defining vocabulary set. A case in point is the lemma lava, which can hardly be defined successfully without a direct reference to a volcano. Seasoned lexicographers are aware of the problem, of course, so in cases like this, rather than talk about some 'mountain with a hole', they will deviate from the principle and nevertheless use the forbidden volcano. The off-the-list status of this word, however, will often be indicated with the use of special typography, commonly lower capitals. In addition, the relevant sense may also be marked with a raised number if the capitalized term happens to have a polysemous entry. This special treatment formally indicates that the word used in the definition lies outside the defining vocabulary set, but also, on a more practical level, signals to the users that they may well find it necessary to cross-refer to the entry for the capitalized term. However, the new factor in the equation is that such an act of cross-reference is, in a well-designed electronic dictionary, a very different operation compared to its traditional paper-book precursor: what used to be laborious page-turning and letter hunting, can now become a simple click of the mouse or even as little as hovering your mouse over the target, with a small popup window providing an instant explanation. In addition, the smart e-dictionary interface will reduce the word to its lemma form, will never mistake the headword for a similar one, and will not get distracted by an irrelevant entry.

Given the relative ease with which instantaneous assistance can now be given (in principle at least, if not always in practice) for problematic words in the definition, it might make good sense to make more liberal use of words outside the strict defining set in an electronic dictionary than in a paper dictionary. Or, perhaps there is room in electronic dictionaries for larger defining vocabulary sets. Care is advised here, as too many infrequent words in a definition may create comprehension problems. We will revisit problems of dictionary definitions and how to help overcome them in section 2.2 below, but now let us move on to another salient lexicographic verbal element: the equivalent.

\subsubsection{Equivalent}

Just as definition is the primary instrument of meaning provision in monolingual dictionaries, so is the equivalent in bilingual dictionaries (see AdamskaSałaciak 2006; 2010 for a detailed discussion of equivalents in bilingual dictionaries). Although the transition to the electronic medium is not likely to radically change lexicographers' way of thinking about dictionary equivalents, recent research (Laufer and Levitzky-Aviad 2006) suggests that L1 $\rightarrow$ L2 electronic dictionaries can potentially benefit from adding instant access from the 
target language equivalents normally given in the entry to more complete information about these items, such as details on their meaning (a similar proposal is made in Bogaards and Hannay 2004).

However, while such enhanced entries might assist in text production and language study, looking up meaning does not seem to be the most salient component of foreign language text production, a process which basically proceeds from concepts (often L1-encoded) to foreign language form. In contrast, meaning indication is primarily relevant in bilingual dictionaries going from L2 to L1, normally used in text decoding. Here, equivalents appear to remain the unchallenged leader when it comes to the job of conveying meaning (Laufer and Hill 2000; Lew and Doroszewska 2009), just as they do for paper dictionaries (Lew 2004).

The above comments do not mean that the electronic medium has nothing to offer in the way of enhancing meaning indication. One case in point would be to design new ways to guide the user to the relevant sense. This is the topic of a recent experimental study by Lew and Tokarek (2010), where the authors test three versions of an experimental online interface to a comprehensive Polish-English dictionary for polysemous entries. The three versions differed in terms of entry navigation devices used. Version One was a plain entry with no extra navigation assistance. Version Two added an entry menu at the top of each entry, as a list of senses accompanied by abbreviated cues, and hyperlinked so that clicking on the specific sense scrolled the display down to the sense proper. Version Three included an entry menu just like that in Version Two, but in addition the target sense in the body of the entry was shown as highlighted against a yellow background, once it was selected from the entry menu. This last version was found to be significantly faster, with a mean access time of 25.6 seconds, compared to 33.2 seconds for the plain menu version and 34.1 seconds for the version with no menu. In addition, the version with sense highlighting yielded mean error rates in the translation task used in the study of about half the magnitude of those in the two simpler interfaces. These findings suggest that target sense highlighting, simple as it is, is a very efficient navigation device even in bilingual dictionaries, where the presence of L1 elements in entries makes scanning long entries less of a problem than would be the case for monolingual dictionaries in a foreign or second language. What is also clear is that it is no longer enough to talk about 'paper' versus 'electronic' dictionaries, but that efficiency will largely depend on the particular solutions adopted (see for instance Tan 2009; Chen 2010; Dziemianko 2010).

\subsubsection{Example}

Examples in dictionaries have a whole range of functions and uses (Fox 1987; Toope 1996; Purczyńska 2002), including some that may not be immediately obvious to users themselves, such as providing guidance on grammar by way of pattern illustration (Bogaards and Van der Kloot 2001, 2002). However, within the focus of this article, the contribution of exemplification to meaning 
indication is most relevant, and in this context it is worth to refer to studies which have found examples and definition to be mutually supportive (Summers 1988; Laufer 1993). Still, a recent study (Al-Ajmi 2008) finds the opposite, so the matter clearly needs further study. One factor that may be responsible for this puzzling disparity may be the quality and type of examples, and this brings us to the issue of the criteria for example selection.

In recent decades, there has been quite a heated debate on the role of corpora in providing examples. Three broad approaches can be identified: corpusderived (examples taken out of corpora with minimal modification), corpusbased (adapted from corpus material), and invented, with arguments being presented for - and against - each of the above (Fox 1987; Cowie 1989; Laufer 1992; Humblé 1998, 2001). Currently, editors of English monolingual learners' dictionaries at least seem to have reached a sort of compromise, mostly going for corpus-based, but modified examples.

While it is generally accepted that text corpora are a good source of examples to be included in a dictionary at the compilation stage, corpora themselves can now form part of an electronic dictionary, and thus offer a useful on-line source of additional examples. Ideally, users should be granted access to additional corpus examples from all the relevant points within an entry, typically in the form of a concordance or some variation thereof. Additional corpus examples may well be a satisfactory solution to the problem of restrictions on how much exemplification a dictionary can provide, due to space constraints $(\mathrm{Xu}$ 2008). One of the first major dictionaries to attempt this was the second edition of COBUILD (Sinclair 1995), which added to its CD-ROM version a 5-millionword sample from the WordBank corpus. However, this innovation was not very well received, perhaps as a result of the rather poor integration between the main text of the dictionary and the corpus sample, or perhaps owing to the disappointing size of the corpus itself.

In this context, it is relevant to mention the GDEX tool (Kilgarriff et al. 2008), an implementation of an algorithm designed to rank corpus citations. Currently, the tool can be accessed in an experimental demo version as part of an automated dictionary of English collocations, available at ForBetterEnglish.com. This is a very promising recent development which could provide future dictionary users with useful corpus-derived examples on demand without flooding them with too much irrelevant material.

\subsection{Audio presentation of verbal elements}

If an electronic dictionary has built-in audio capability, then it is in principle possible to present the verbal components of the entry (such as the headword, definition, or example), not just in conventional spelling, but as the spoken word. In this case, spoken could refer to voice recordings of a human reader, or else to synthesized speech, the latter not being very popular at this point, but this might change in the near future as speech synthesis techniques get better. While it is becoming something of an industry standard to offer audio re- 
cordings of the headword itself, users could conceivably benefit from audio representation of other microstructural elements, notably the definition and examples.

Apart from their unquestioned attractions, spoken definitions and examples have less immediately obvious potential benefits. We have already (section 2.1.1 above) pointed to some problems with the use of restricted defining vocabulary in learners' dictionaries. Beyond those already mentioned, there is at least one more disadvantage: simplifying the lexis often requires compensatory strategies on the part of the definer, so that the simpler vocabulary may come at the cost of increased grammatical complexity (such as the addition of modifying clauses) and longer definitions. In fact, any of these two can lead to parsing problems, with users experiencing difficulty segmenting the definition correctly into phrasal components. This difficulty is particularly likely to be felt by non-native speakers or learners, owing to their imperfect command of the language. For them, an opportunity to hear the definition being read out aloud, and not just printed in ordinary orthography, offers the helpful cues inherent in the prosodic characteristics of speech: stress, rhythm, and intonation. This additional layer is likely to provide assistance in conveying the syntacticstructural composition of the definition to the users, thus helping them to segment, and ultimately understand, the definition better. This in addition to the expected long-term benefits of being exposed to authentic pronunciation. The same rationale might apply to examples; in fact, LDOCE4 in its CD-ROM version already provides digitized audio recordings of examples. ${ }^{2}$

In addition, audio presentation would afford dictionary users an opportunity to get more exposure to so-called 'real language' - here in the sense of speech rather than writing, while also serving as a pronunciation model. If we endorse the general trend observable in English Monolingual Learners' Dictionaries to make definitions more like teachers talking to students, then presenting definitions in audio format is certainly much closer to teachers talking than the traditional printed definitions.

Much as the idea of spoken definitions seems theoretically attractive, user studies are needed to establish to what extent the benefits of definitions (and examples) in audio format are real and significant. Some positive evidence is, however, already available when it comes to audio recordings of lemmas. Laufer and Hill (2000) examined the options selected for meaning representation in an innovative experimental electronic dictionary interface by Israeli and Chinese (Hong Kong) learners of English at university level. The options available to users were: L1 translation, L2 definition, illustrative examples, etymology, 'extra' information (i.e. other forms of the word, phonemic transcription, register, complementation, related meanings, and other semantic and syntactic details), and spoken recordings of headwords. A comparison of the two groups of subjects revealed that the Chinese students referred to recorded pronunciations significantly more frequently than the Israeli subjects, and doing so helped them retain the meaning of the consulted items better. The authors explain that one possible reason for the enhanced value of spoken forms for 
Chinese users might be that 'Chinese preference for the pronunciation option could somehow be related to the fact that Chinese dictionaries are arranged according to the phonetic radical and so Chinese lookup (sic) words in a dictionary by sound' (Laufer and Hill 2000: 70). This is an important observation underscoring the point that the specific solutions adopted by electronic dictionary makers need to take cognizance of the particularities of the language(s) being treated as well as the needs and habits of prospective users.

\section{$2.3 \quad$ Non-verbal mode}

Verbal representation of meaning has been the cornerstone of lexicographic practice for centuries, and although it remains just as important today, traditional lexicography is not exclusively about words: pictorial illustrations have also established a presence in paper lexicography. This, plus some other electronic-only options (not possible on printed paper) will be discussed below.

Before we move on to the discussion of such visual elements, however, let us dwell for a while longer on audio recordings, but this time recordings, not of spoken linguistic forms, but rather of non-linguistic sounds.

\subsubsection{Audio recordings of non-linguistic sounds}

Audio clips in an electronic dictionary need not be restricted to the duplication of lexicographic data in printed form. This potential of e-dictionaries was already noted by Dodd (1989: 91), who postulated the inclusion of audio clips for selected entries, specifically for onomatopoeic words. Ooi (1998: 112) argues that an actual recording of the sound of a bell would contribute more to the explanation of meaning than a mere verbal description, or a picture of it. Ooi's observation can be generalized to other lexical items for which the sound is an important and recognizable component of meaning. In fact, there are dictionaries that already offer this: the online Macmillan English Dictionary (Rundell 2007) includes the so-called sound effects (the term also originally used by Dodd). Among those, we find the recordings of sounds of musical instruments under their names, including the common ones such as GUITAR, PIANO, VIOLIN, RECORDER, as well the less-widely known instruments such as SITAR. We also find animal and bird calls, such as the roar of a lion under ROAR (but not under LION), or the hoot of an owl under HOOT (but not under OWL). Sounds made by humans, voluntary or otherwise, are also well represented (cf. the entries for CLAP, LAUGH, or HICCUP).

\subsubsection{Pictorial illustration (static)}

Although, by conventional wisdom, a picture is worth a thousand words, not all vocabulary items can be usefully, or indeed at all, illustrated. This is the reason why pictorial dictionaries will not pack a wordlist (nomenclature) compara- 
ble to that of a general dictionary, and an illustrated dictionary will only choose to include pictorials for a selection of its entries (and senses). For instance, according to the information in the front matter (Summers 1987: F49), LDOCE2 aims to add illustrations for the following four categories of items:

(a) common animals, plants, objects;

(b) things not easily explained in words, such as shapes, complex actions;

(c) groups of related words; and

(d) basic meaning of words often used in a figurative or abstract way.

Stein (1991) gives a fuller and more detailed list of items for which lexicographic illustrations are used, based on her analysis of several dictionaries, including two English learners' dictionaries. Ilson (1987), on the other hand, adopts a broader concept of dictionary illustration which also includes tables and diagrams. There appears to be, then, a fairly good understanding of what types of items may potentially be complemented with illustrations. The practical question, though, is whether adding pictures offers real benefits to the dictionary user. In this connection, let us look next at two relevant studies.

Nesi (1998) investigated the effectiveness of illustrations in conveying the meaning of everyday household objects. Her target items were: colander, insole, plunger, shoehorn and spout; and all had clearly recognizable visual features. In her experiment, Nesi observed that her subjects, in the majority undergraduate students who where not native speakers of English, were frequently at a loss identifying actual meanings based on definitions and examples alone, but they would often correctly identify the object once confronted with a picture. This finding indicates that verbal explanation of meaning by way of definition and example can benefit from the addition of pictorial illustrations.

In her study, Nesi did not offer subjects an equivalent in their native language. This was done in a more recent study by Gumkowska (2008), which focused on vocabulary retention by twenty Polish learners of English from bilingual-dictionary-like concrete noun entries with and without pictures, again using concrete noun vocabulary items. Gumkowska (at the advice of the present author in the role of thesis supervisor) adopted a cross-balanced design, so that one version of the task included pictures for half the entries, while the other version illustrated the other entries. This way, each subject was exposed to both illustrated and unillustrated types of entries, and each entry was presented under two conditions in equal measure, thus compensating for the confounding influence of the effects of item and subject. I have calculated the retention rate for the picture-enhanced headwords to be close to $80 \%$, compared with $70 \%$ for the entries with bare Polish translations, and this difference turned out to be statistically significant by a paired T-test $\left(\mathrm{T}_{(\mathrm{df}=38)}=2.58\right.$, $\mathrm{p}=0.014$ ), despite the small sample size.

The two studies point to double benefits of pictorial illustrations as an additional meaning indicator in dictionaries, at least for concrete nouns. As shown by Nesi, pictures help with immediate recognition and comprehension, 
which is often the primary function of dictionaries. But the benefits do not stop there, as the presence of pictures also promotes vocabulary acquisition in the foreign language, as evidenced by Gumkowska's study.

If illustrations are indeed as effective as the two studies indicate, the natural course for lexicographers to take would be to try and include a larger number of illustrations in dictionaries. In paper dictionaries, this option has always been constrained by two factors: cost and storage space. Illustrations tend to be more expensive and problematic in the process of typesetting and printing. They also cannot be very small, or else they will lose clarity and the benefits will be diminished or lost. In a printed book, every single picture included adds to the size of the volume, and this, indirectly, again impacts cost, as well as making the dictionary bulky and unwieldy. But with the large and expanding storage capacity of most types of electronic dictionaries (standalone devices and resident dictionaries for mobile phones may be something of an exception), including pictorial illustrations for a larger number of entries and senses than has been usual in paper dictionaries is a compelling prospect. However, one should not forget that the total storage space of a dictionary is not the same as its presentation space (roughly, how much data it can display to the user at a time; see Lew (in press) for details). The latter is still about as restricted as it is in paper dictionaries, and more so on handheld devices, including mobile-phonebased dictionaries. The fundamental technical problem at present is the difficulty of combining portability and small device size with a comfortably large display. Perhaps a radical solution becomes available in the near future in the form of projector glasses, which would display an image on the inside of their lenses for the wearer to view, thus utilizing a large fraction of the human field of vision. In the not-so-near future, 3D holographic projectors may become a possibility, but for the moment this is the stuff of science fiction rather than science.

Another issue which may be affected by technological change is the use of colour in illustrations. Colour printing tends to be expensive (though it has become more affordable in recent years); in contrast, colour displays are now the default on electronic devices except in some types of handheld portables, and in e-book readers. This means that cost ceases to be an important consideration in choosing between black-and-white and colour illustrations, and the latter can be used more liberally. Having said that, there is no evidence that full-colour illustrations are in fact more effective in dictionaries than the more traditional simple iconic line drawings. This last point is related to another choice: that between drawings and photographs, which we now turn to.

\subsubsection{Photographs}

With today's easy-to-use and efficient digital cameras, photographs may often be the quicker, cheaper, and easier choice than drawings, at least for everyday objects within easy reach. Photographs can be included in electronic dictionar- 
ies more readily than on paper, particularly if the device is equipped with a colour screen. However, photographs may not be without problems. In terms of prototype theory, it is probably easier to represent a 'prototypical' bird, chair or car, than it is by means of a photograph. The latter usually includes a lot of detail, and there is the real danger of the user interpreting some irrelevant detail as criterial for the concept being defined. Further, a hand drawing can emphasize what the focus is, i.e. which part of the pictorial illustration represents the object (and lexical item) in question. The artist can foreground and background the various elements of the picture as needed, providing subtle clues to the user consulting the entry. For example, to properly represent a fin in an illustration, it has to be shown in the context of a fish as a whole; at the same time, users need an indication that the word does not denote the whole fish. A professional artist can utilize a variety of techniques such as broken lines, shading and pointing arrows singling out components of the picture. Figure 1 below illustrates how this could be done. Still, manipulating a photograph to achieve a similar effect, such as adding an arrow pointing at the designate in the picture, is also possible, and occasionally one does come across such techniques in dictionaries.

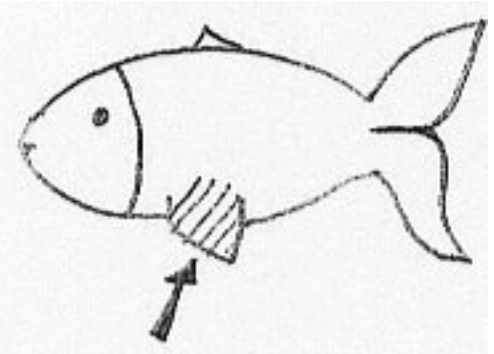

Figure 1: An illustrative picture for the entry fin. Note the use of shading and an arrow as foregrounding devices to prevent the mistaken identification of the lemma sign with the designate of the holonymic fish (after Gumkowska 2008).

\subsubsection{Graphs}

Iconic illustrations and photographs may be useful for illuminating the meaning of concrete objects, but what about words expressing more abstract relations, such as prepositions? These are the kinds of words whose lexicographic treatment even in the leading dictionaries still leaves one dissatisfied (Coffey 2006). Adamska-Sałaciak (2008) advocates the inclusion of schematic graphs to represent the meaning of prepositions, and an example for the prepositions above, over, under and below is given in Figure 2. Of course, such a graph will not provide an exhaustive explanation of all the numerous senses and uses of the word, but will nevertheless present a schematic of the most central spatial senses. 


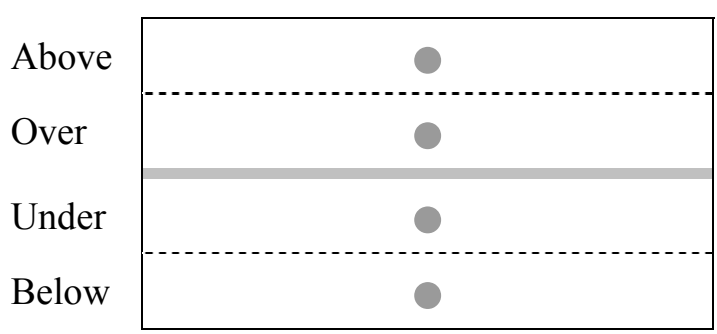

Figure 2: A graph proposed for inclusion in bilingual dictionaries as a comparison of the English prepositions above, over, under and below (Adamska-Sałaciak 2008: 1482)

It would seem that graphs of this and similar types might also be useful in the representation of various meaning relations. A particularly convincing implementation of the effective visualization of meaning relations is the Visuwords interface (www.visuwords.com), here serving as a front-end to English WordNet data; but it could be used with other lexical databases as long as it can be made to 'understand' the structure. An example entry for the lemma motor is shown in Figure 3 below.

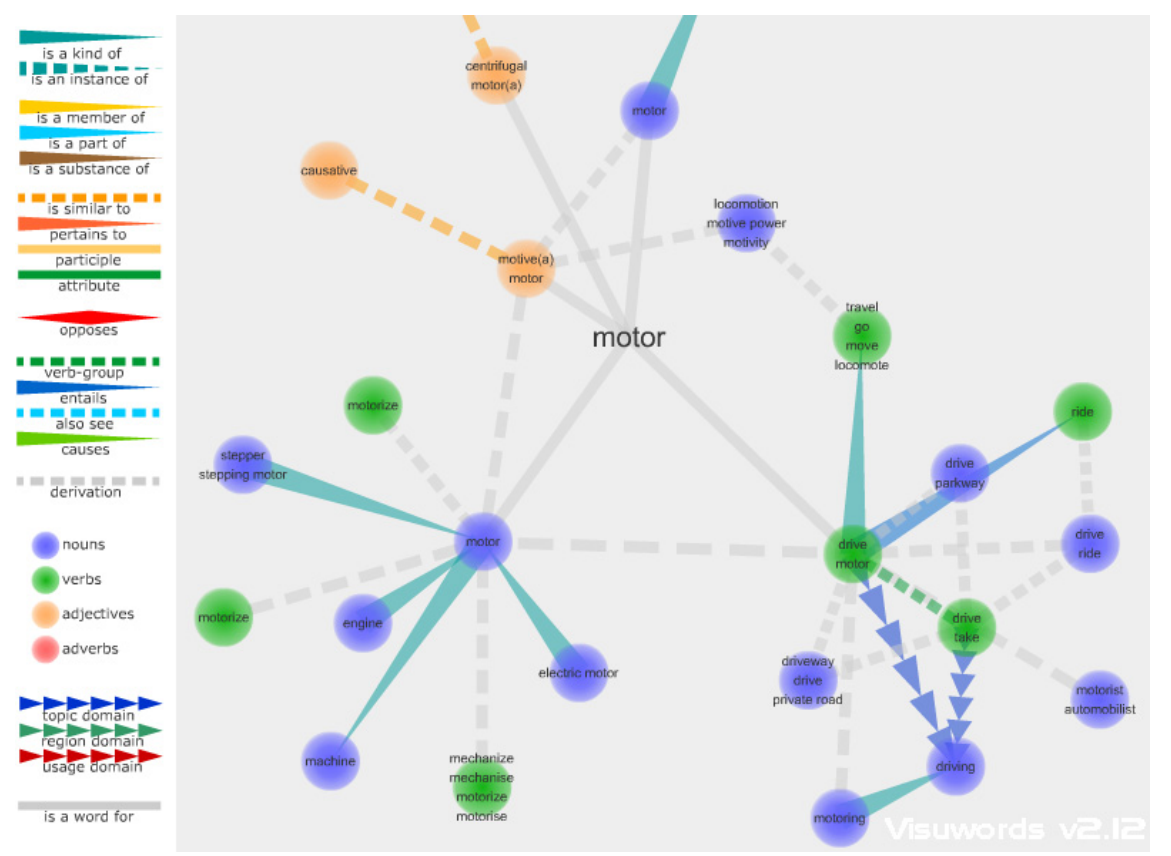

Figure 3: A floating quasi-3D graph illustrating sense relations for the entry motor in the Visuwords interface (http://www.visuwords.com/ ?word=motor) 


\subsubsection{Animation}

Some of Stein's (1991: 109-111) illustratable categories actually involve, not one, but a series of static pictures. Herewith lie countable nouns shown in 'different sides or aspects ... to capture different dimensions or stages of use', an example of which is concertina; and perhaps even more so Stein's category 3, 'countable nouns that denote an event or an activity that is realized by a number of event or action phases', such as eclipse and press-up/push up. Another group are action verbs such as dive, erupt and bend. In entry types such as the above, it is hard to escape the impression that animated illustrations would form a perfect medium for conveying to the user the stages or progression of an action.

This was what Lew and Doroszewska (2009) expected to find in their study of animations in on-line dictionary entries, in which Polish learners of English were asked to read a short story online and look up unknown words in an online experimental dictionary interface. To help them understand the more difficult words, users could view any combination of the following: Polish translation, English definition, example sentences, and animated picture. Every detail of online behaviour was logged, and subjects were subsequently tested on meaning recall of the target items, which were verbs describing actions of the body and facial expressions such as shiver, blush and frown, believed to be well representable by means of animation. Quite unexpectedly, ${ }^{3}$ consulting animations did not turn out to have helped Polish students remember the meanings better, and in fact a strong and statistically significant negative effect of viewing animation on item retention was found. Why would animations have had a negative effect on retention? One possibility is that animations distracted subjects from the form-meaning relationship, which is essential for successful retention. Another possible reason is that the actual animations used in the study could have been misleading: although some initial piloting was done and no problems were found, plus all those subjects who viewed animations also consulted Polish equivalents, so it is not likely that they actually misunderstood the items. Whatever the reason, the outcome invites the recommendation that animations in future electronic dictionaries be used cautiously and sparingly, at least before more evidence becomes available on the effectiveness of animations for different types of entries.

\subsubsection{Video clips}

Video sequences are the most demanding type of lexicographic data in terms of storage space; plus, they tend to be expensive and difficult to produce. Also, for the user to watch a video clip takes some time; this means that the consultation act cannot be quick, which is a fundamental consideration in dictionary use, at least for Hausmann's selective (German punktuell) type of dictionary consultation (Hausmann 1977: 144). Further, as pointed out by Chun and Plass (1996), the nature of video sequences is such that they are too transient for the viewer 
to build a stable mental model. This is different from static pictures, which can be examined for as long as the user wishes. The risk of a mismatch between the user's cognitive pace and the timing of the visual presentation is one disadvantage that video clips appear to share with animated pictures, and this factor could account for the poor effectiveness of animations (cf. 2.3.5 above). If video clips are to be useful in dictionaries, it is likely to be in connection with the learning function of the dictionary, to provide assistance with items such as conventionalized exchanges, pragmatic pairs, etc. (e.g. asking the way). Videos, with their rich contextualization, can convey useful information on the pragmatic and situational context of linguistic communication. Some video sequences have already been included in learners' dictionaries, such as in LDOCE4 (Summers 2003), although somehow they are no longer offered in the latest fifth edition (Mayor 2009).

\section{Closing comments}

One area of lexicography which could perhaps benefit significantly from the multimodal approach is LSP dictionaries. This is the approach proposed by Talib (2009) for a dictionary of narration. Talib cites filmmaking terms such as 'flashback', 'voice-over narration' and 'point-of-view shot', predicting that 'the possibility is very real that some specialist dictionaries of the future may end up not consisting of words, but videos, pictures and non-linguistic sounds, and other videos, pictures and non-linguistic sounds will be used to "define" them' (Talib 2009: 258).

Unlike Talib, I would not go so far as to expect words to surrender their leading role in lexicographic meaning explanation. However, given the technical potential of modern electronic dictionaries, various possibilities present themselves of complementing the traditional verbal explanation. The expectation is that multi-modal processing should engage the dictionary user more and bring about improved comprehension and knowledge acquisition, but in practice this is not always so. Clearly, much more research is needed before we are able to identify the optimal combination of ways of presenting meaning in dictionaries. It should not be surprising if the solutions turn out to be sensitive to factors such as dictionary culture, consultation goals and context, level of proficiency in the language and specialized domain, and type of lexical item.

\section{Endnotes}

1. No systematic attempt is made in this article to address other aspects of electronic lexicography; the reader could study De Schryver (2003) on the subject.

2. Audio recordings are also available in the free online version at http://www.ldoceonline.com, but only for words beginning with the letters $\mathrm{D}$ and $\mathrm{S}$.

3. It is the subversion of such seemingly inescapable expectations that underscores the importance of experimental user research, pace Tarp (2009). 


\section{References}

Adamska-Sałaciak, A. 2006. Meaning and the Bilingual Dictionary: The Case of English and Polish. Frankfurt am Main: Peter Lang.

Adamska-Sałaciak, A. 2008. Prepositions in Dictionaries for Foreign Learners: A Cognitive Linguistic Look. Bernal, E. and J. DeCesaris (Eds.). 2008: 1477-1485.

Adamska-Sałaciak, A. 2010. Examining Equivalence. International Journal of Lexicography: Advance Access published online on July 23, 2010.

Al-Ajmi, H. 2008. The Effectiveness of Dictionary Examples in Decoding: The Case of Kuwaiti Learners of English. Lexikos 18: 15-26.

Bernal, E. and J. DeCesaris (Eds.). 2008. Proceedings of the XIII EURALEX International Congress, Barcelona, 15-19 July 2008. Sèrie Activitats 20. Barcelona: Universitat Pompeu Fabra.

Bogaards, P. and M. Hannay. 2004. Towards a New Type of Bilingual Dictionary. Williams, G. and S. Vessier (Eds.). 2004. Proceedings of the Eleventh EURALEX International Congress, EURALEX 2004, Lorient, France, July 6-10, 2004, Volume 2: 463-474. Lorient: Université De Bretagne Sud.

Bogaards, P. and W.A. Van der Kloot. 2001. The Use of Grammatical Information in Learners' Dictionaries. International Journal of Lexicography 14(2): 97-121.

Bogaards, P. and W.A. Van der Kloot. 2002. Verb Constructions in Learners' Dictionaries. Braasch, A. and C. Povlsen (Eds.). 2002. Proceedings of the Tenth EURALEX International Congress, EURALEX 2002, Copenhagen, Denmark, August 13-17, 2002: 747-757. Copenhagen: Center for Sprogteknologi, Copenhagen University.

Chen, Y. 2010. Dictionary Use and EFL Learning. A Contrastive Study of Pocket Electronic Dictionaries and Paper Dictionaries. International Journal of Lexicography: Advance Access published online on May 24, 2010.

Chun, D.M. and J.L. Plass. 1996. Effects of Multimedia Annotations on Vocabulary Acquisition. Modern Language Journal 80(2): 183-198.

Coffey, S. 2006. High-Frequency Grammatical Lexis in Advanced-Level English Learners' Dictionaries: From Language Description to Pedagogical Usefulness. International Journal of Lexicography 19(2): 157-173.

Cowie, A.P. 1989. The Language of Examples in English Learner's Dictionaries. James, G. (Ed.). 1989: 55-65.

Cowie, A.P. 1999. English Dictionaries for Foreign Learners: A History. Oxford: Clarendon Press.

De Schryver, G.-M. 2003. Lexicographers' Dreams in the Electronic-Dictionary Age. International Journal of Lexicography 16(2): 143-199.

Dodd, W.S. 1989. Lexicomputing and the Dictionary of the Future. James, G. (Ed.). 1989: 83-93.

Dziemianko, A. 2010. Paper or Electronic? The Role of Dictionary Form in Language Reception, Production and the Retention of Meaning and Collocations. International Journal of Lexicography: Advance Access published online on February 1, 2010.

Fabiszewski-Jaworski, M. and M. Grochocka. 2010. Folk Defining Strategies vs. Comprehension of Dictionary Definitions: An Empirical Study. Kernerman, I. and P. Bogaards (Eds.). 2010. English Learners' Dictionaries at the DSNA 2009: 89-105. Tel Aviv: K Dictionaries.

Fox, G. 1987. The Case for Examples. Sinclair, J. (Ed.). 1987: 137-149.

Gumkowska, A. 2008. The Role of Dictionary Illustrations in the Acquisition of Concrete Nouns by Primary School Learners and College Students of English. Unpublished B.A. Thesis. Szczecin: Collegium Balticum.

Hanks, P. 1987. Definitions and Explanations. Sinclair, J. (Ed.). 1987: 116-136. 
Hausmann, F.J. 1977. Einführung in die Benutzung der neufranzösischen Wörterbücher. Tübingen: Niemeyer.

Humblé, P. 1998. The Use of Authentic, Made-up and 'Controlled' Examples in Foreign Language Dictionaries. Fontenelle, T., P. Hiligsmann, A. Michiels, A. Moulin and S. Theissen (Eds.). 1998. EURALEX '98 Proceedings. Papers Submitted to the Eighth EURALEX International Congress on Lexicography in Liège, Belgium: 593-599. Liège: English and Dutch Departments, University of Liège.

Humblé, P. 2001. Dictionaries and Language Learners. Frankfurt am Main: Haag und Herchen.

Ilson, R.F. 1987. Illustrations in Dictionaries. Cowie, A.P. (Ed.). 1987. The Dictionary and the Language Learner: 193-212. Lexicographica Series Maior 17. Tübingen: Niemeyer.

James, G. (Ed.). 1989. Lexicographers and their Works. Exeter Linguistic Studies 14. Exeter: Exeter University Press.

Kilgarriff, A., M. Husak, K. McAdam, M. Rundell and P. Rychlý. 2008. GDEX: Automatically Finding Good Dictionary Examples in a Corpus. Bernal, E. and J. DeCesaris (Eds.). 2008: 425432.

Laufer, B. 1992. Corpus-Based versus Lexicographer Examples in Comprehension and Production of New Words. Tommola, K.H., K. Varantola, T. Salmi-Tolonen and J. Schopp (Eds.). 1992. EURALEX '92 Proceedings. Papers Submitted to the 5th EURALEX International Congress, Tampere 1992: 71-76. Tampere: Department of Translation Studies, University of Tampere.

Laufer, B. 1993. The Effect of Dictionary Definitions and Examples on the Use and Comprehension of New L2 Words. Cahiers de Lexicologie 63(2): 131-142.

Laufer, B. and M. Hill. 2000. What Lexical Information Do L2 Learners Select in a CALL Dictionary and How Does it Affect Word Retention? Language Learning E Technology 3(2): 58-76.

Laufer, B. and T. Levitzky-Aviad. 2006. Examining the Effectiveness of 'Bilingual Dictionary Plus' - a Dictionary for Production in a Foreign Language. International Journal of Lexicography 19(2): 135-155.

Lew, R. 2004. Which Dictionary for Whom? Receptive Use of Bilingual, Monolingual and Semi-Bilingual Dictionaries by Polish Learners of English. Poznań: Motivex.

Lew, R. In press. Space Restrictions in Paper and Electronic Dictionaries and Their Implications for the Design of Production Dictionaries. Bański, P. and B. Wójtowicz (Eds.). In press. Issues in Modern Lexicography. Munich: Lincom Europa.

Lew, R. and J. Doroszewska. 2009. Electronic Dictionary Entries with Animated Pictures: Lookup Preferences and Word Retention. International Journal of Lexicography 22(3): 239-257.

Lew, R. and A. Dziemianko. 2006. A New Type of Folk-Inspired Definition in English Monolingual Learners' Dictionaries and Its Usefulness for Conveying Syntactic Information. International Journal of Lexicography 19(3): 225-242.

Lew, R. and P. Tokarek. 2010. Entry Menus in Bilingual Electronic Dictionaries. Granger, S. and M. Paquot (Eds.). 2010. Elexicography in the 21st Century: New Challenges, New Applications: 193202. Louvain-la-Neuve: Cahiers du CENTAL.

Mayor, M. (Ed.). 2009. Longman Dictionary of Contemporary English. Fifth Edition. Harlow: Longman.

McCreary, D.R. and E. Amacker. 2006. Experimental Research on College Students' Usage of Two Dictionaries: A Comparison of the Merriam-Webster Collegiate Dictionary and the Macmillan English Dictionary for Advanced Learners. Corino, E., C. Marello and C. Onesti (Eds.). 2006. Atti Del XII Congresso Di Lessicografia, Torino, 6-9 Settembre 2006: 871-885. Allessandria: Edizioni dell'Orso. 
Nesi, H. 1998. Defining a Shoehorn: The Success of Learners' Dictionary Entries for Concrete Nouns. Atkins, B.T.S. (Ed.). 1998. Using Dictionaries. Studies of Dictionary Use by Language Learners and Translators: 159-178. Lexicographica. Series Maior 88. Tübingen: Niemeyer.

Ooi, V.B.Y. 1998. Computer Corpus Lexicography. Edinburgh: Edinburgh University Press.

Purczyńska, E. 2002. Examples in the Bilingual Dictionary: An Empirical Study. Unpublished M.A. Thesis. Poznań: School of English, Adam Mickiewicz University.

Rundell, M. (Ed.). 2007. Macmillan English Dictionary. (MED2.) London: Macmillan.

Sinclair, J. (Ed.). 1987. Looking Up: An Account of the COBUILD Project in Lexical Computing. London/Glasgow: Collins.

Sinclair, J. (Ed.). 1995. Collins COBUILD English Language Dictionary. Second Edition. (COBUILD2.) London: HarperCollins.

Stein, G. 1991. Illustrations in Dictionaries. International Journal of Lexicography 4(2): 99-127.

Summers, D. (Ed.). 1987. Longman Dictionary of Contemporary English. Second Edition. (LDOCE2.) Harlow: Longman.

Summers, D. 1988. The Role of Dictionaries in Language Learning. Carter, R. and M. McCarthy (Eds.). 1988. Vocabulary and Language Learning: 111-125. London: Longman.

Summers, D. (Ed.). 2003. Longman Dictionary of Contemporary English. Fourth Edition. (LDOCE4.) Harlow: Longman.

Talib, I.S. 2009. Towards a Multimodal Dictionary of Narration. Ooi, V.B.Y., A. Pakir, I.S. Talib and P.K.W. Tan (Eds.). 2009. Perspectives in Lexicography: Asia and Beyond. New and Selected Papers from the Fourth Asialex International Conference, National University of Singapore. Papers on Lexicography and Dictionaries, Volume 1: 249-258. Tel Aviv: K Dictionaries.

Tan, K.H. 2009. How Effective Is the Electronic Dictionary in Sense Discrimination? Lexikos 19: 262274.

Tarp, S. 2009. Reflections on Lexicographical User Research. Lexikos 19: 275-296.

Toope, M. 1996. Examples in the Bilingual Dictionary. Unpublished M.A. Thesis. Ottawa: University of Ottawa.

Walter, E. (Ed.). 2005. Cambridge Advanced Learners' Dictionary. Second Edition. (CALD2.) Cambridge: Cambridge University Press.

Wierzbicka, A. 1985. Lexicography and Conceptual Analysis. Ann Arbor: Karoma.

Xu, H. 2008. Exemplification Policy in English Learners' Dictionaries. International Journal of Lexicography 21(4): 395-417. 